University of South Florida

DIGITAL COMMONS

Digital Commons @ University of

@ UNIVERSITY OF SOUTH FLORIDA

South Florida

USF Tampa Graduate Theses and Dissertations

USF Graduate Theses and Dissertations

3-17-2015

\title{
Using Token Reinforcement to Increase Walking for Adults with Intellectual Disabilities
}

Haley Nicole Krentz

University of South Florida, haleykrentz@gmail.com

Follow this and additional works at: https://digitalcommons.usf.edu/etd

Part of the Psychology Commons

\section{Scholar Commons Citation}

Krentz, Haley Nicole, "Using Token Reinforcement to Increase Walking for Adults with Intellectual Disabilities" (2015). USF Tampa Graduate Theses and Dissertations.

https://digitalcommons.usf.edu/etd/5530

This Thesis is brought to you for free and open access by the USF Graduate Theses and Dissertations at Digital Commons @ University of South Florida. It has been accepted for inclusion in USF Tampa Graduate Theses and Dissertations by an authorized administrator of Digital Commons @ University of South Florida. For more information, please contact digitalcommons@usf.edu. 
Using Token Reinforcement to Increase Walking for Adults with Intellectual Disabilities

by

Haley Nicole Krentz
A thesis submitted in partial fulfillment
of the requirements for the degree of
Master of Arts
Department of Child and Family Studies
College of Behavioral and Community Sciences
University of South Florida
Major Professor: Raymond Miltenberger, BCBA-D
Kimberly Crosland, Ph.D., BCBA-D
Andrew Samaha, Ph.D., BCBA-D

Date of Approval:

March 17, 2015

Keywords: physical activity, distance, social support, work site

Copyright (C) 2015, Haley Krentz 


\section{Dedication}

I dedicate this manuscript to my parents, Paul and Beth, for their unconditional love and support throughout my life's endeavors, inspiring me to pursue my passions and achieve my goals. 


\section{Table of Contents}

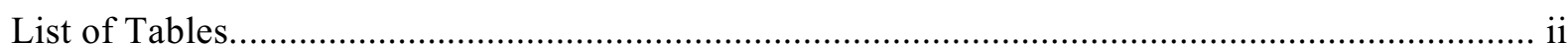

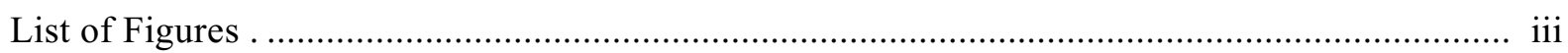

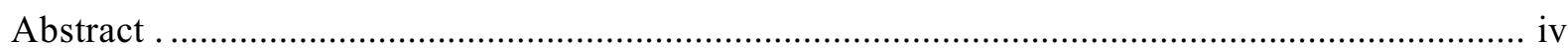

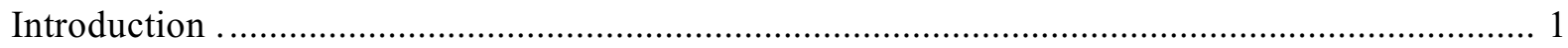

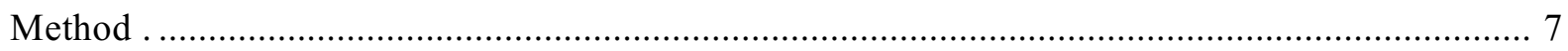

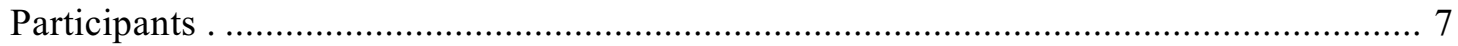

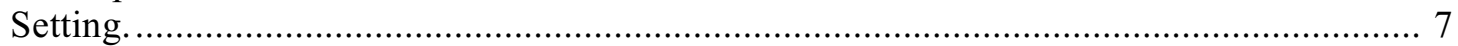

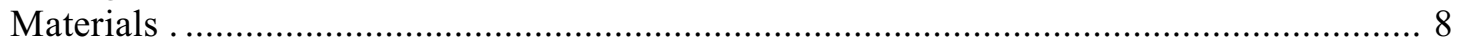

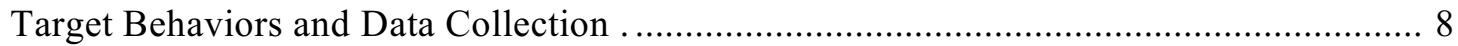

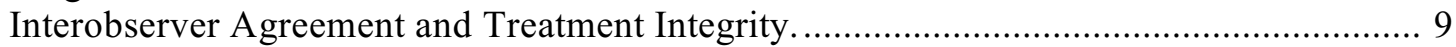

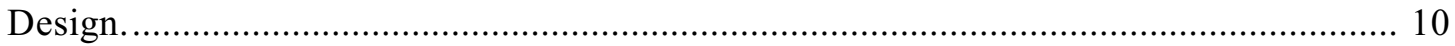

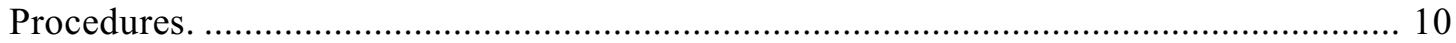

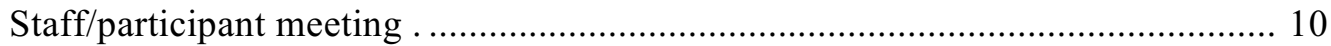

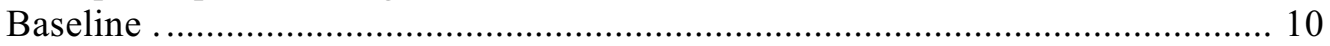

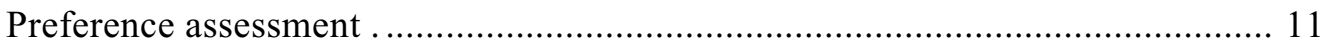

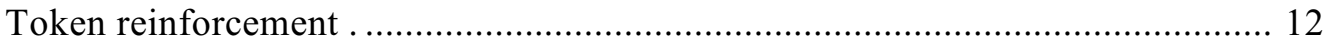

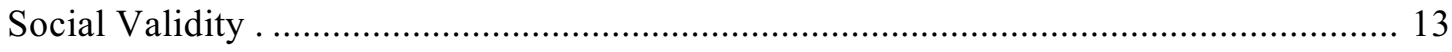

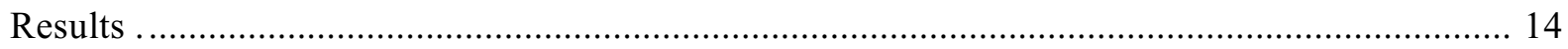

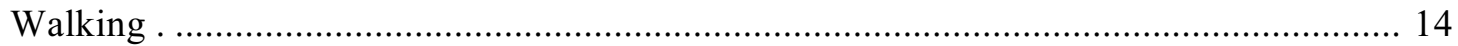

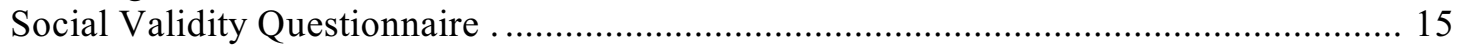

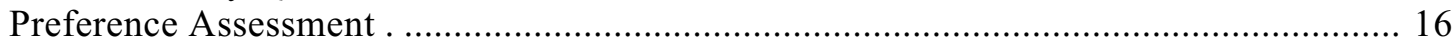

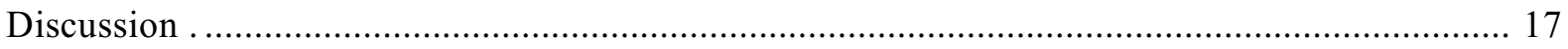

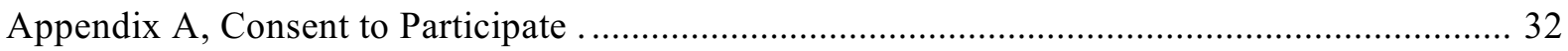

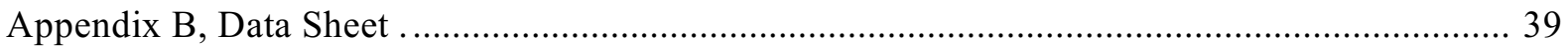

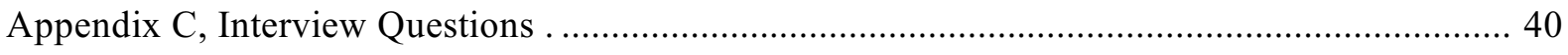

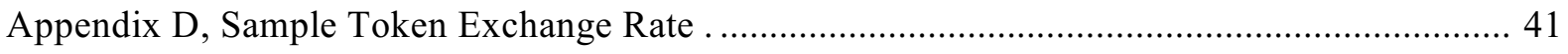

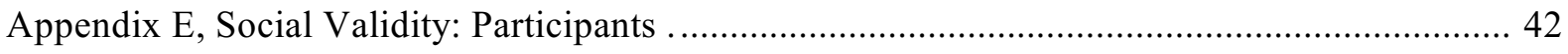

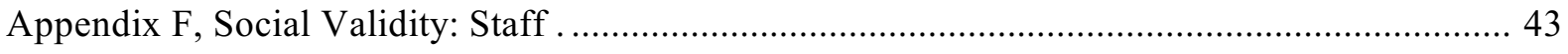

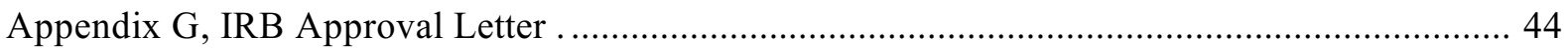




\section{List of Tables}

Table 1: Items selected in the preference assessment, percentages of reinforcers chosen,

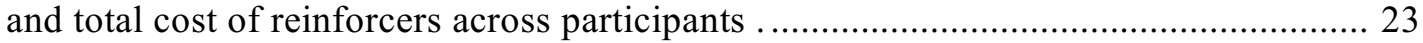




\section{List of Figures}

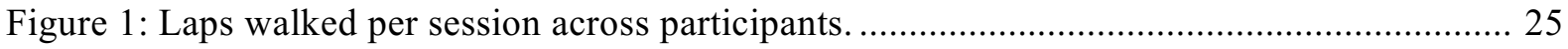




\begin{abstract}
Adults with intellectual disabilities (ID) are at risk for negative health conditions due to high levels of sedentary behavior. Walking and cycling are the most common forms of physical activity engaged in by adults with ID. Research is limited in evaluating physical activity interventions for this population. The purpose of this study will be to evaluate the effectiveness of a token reinforcement intervention to increase distance walked for adults with mild to moderate ID at adult day training centers.
\end{abstract}




\section{Introduction}

Physical activity is defined as any movement exerted by the skeletal muscles that results in

energy expenditure (Caspersen, Powell, \& Christenson, 1985). Physical activity is important because inactivity or sedentary behavior is the fourth leading risk for mortality worldwide(Winter, Bastiaanse, Hilgenkamp, Evenhuis, \& Echetld, 2011; World Health Organization [WHO], 2014). Inactivity contributes to serious health problems including cardiovascular disease, cancers, diabetes, hypertension, and stroke. Globally, one in three adults is inactive and therefore at risk for the negative health conditions stated above (US Department of Health and Human Services [USDHHS], 2008; WHO, 2014). Within the United States, approximately one-third of adults live sedentary lifestyles, walking fewer than 5000 steps per day, and fail to engage in activity to combat these lifestyle diseases. Any activity, regardless of intensity level, is beneficial to those who currently engage in a sedentary lifestyle (Centers for Disease Control and Prevention [CDC], 2014; Conn, Hafdahl, \& Mehr, 2011; Finlayson et al., 2009; Finlayson,Turner, \& Granat, 2011; Ginis, Nigg, \& Smith, 2013; Heller, Fisher, Marks \& Hsieh, 2014;King, Rejeski, \& Buchner, 1998; Lante, Walkley, Gamble, \& Vassos, 2011; Mendonca, Pereira,\& Fernhall, 2010; Temple, Anderson, \& Walkley, 2000; Winter et al., 2011; WHO, 2014).

One population that is likely to be inactive is individuals with intellectual disabilities (ID). Adults with ID are at a greater risk for being inactive and sedentary compared to typical peers (Bazzano et al., 2009; Bodde, Seo, Frey, Van Puymbroeck, \& Lohrmann, 2013; Finlayson et al., 2009, 2011; Heller et al., 2014; Hilgenkamp, Reis, van Wijck, \& Evenhuis, 2012; Hsieh, 
Rimmer, \& Heller, 2013; Lante et al., 2011; Melville, Hamilton, Hankey, Miller, \& Boyle, 2007; Mendonca et al., 2010; Peterson, Janz, \& Lowe, 2008; Robertson et al., 2000; Temple, Frey, \&Stanish, 2006; Winter et al., 2011). Almost one third of adults with ID never or rarely engage in moderate to vigorous physical activity or MVPA (Hsieh et al., 2013). As inactivity leads to being overweight and obese, adults with disabilities have poorer health outcomes than typical peers (Bazzano et al, 2009; Bodde et al., 2013; Fernhall et al., 1996; Finlayson et al., 2009, 2011; Hsieh et al., 2013; Mendonca et al., 2010; Temple et al., 2006).

Research attests to the lower levels of physical fitness for individuals with Down Syndrome (DS) in particular. Comorbid symptoms of low maximal heart rates, respiratory abnormalities, circulatory issues, and muscle weakness make independent, functional living activities more challenging for individuals with DS compared to peers with other diagnoses of ID or typical peers (Carmeli, Kessel, Coleman, \& Ayalon, 2002; Crowley et al., 2011; Dodd \&Shields, 2005; Mendonca, Pereira, \& Fernhall, 2013; Shield \& Taylor, 2010). With poorer health outcomes, further implications for those who have DS and live sedentary lifestyles include decreases in life longevity and fewer opportunities for independent living (WHO, 2014). These consequences impact the quality of life and overall independence these individuals experience.

The prevalence of medical conditions experienced by individuals with ID makes visits to a doctor routine. However, physical activity is rarely addressed during physician visits. Other health concerns take precedence, resulting in little communication about resources available for individuals with disabilities to become active. For those that are told they are at risk for serious health concerns due to weight and or inactivity, instructions or interventions for weight loss are rarely provided (Dorgo, Robinson, \& Bader, 2009; Hawkins, Stegall, Weber, \& Ryan, 2012;Hsieh et al., 2013; RelMoya, Castilla-Alvarex, Pichiule-Castaneda, Rico-Blazquex, Escortell- 
Mayor, \& Gomez-Quevedo, 2012). Caregivers of those with disabilities may also be naïve to the negative health effects of inactivity. Janicki et al. (2002) found that caregivers reported the health status of $81 \%$ of the sample of individuals with ID to be good to excellent, when over half were sedentary individuals and categorized as obese. It is unlikely that a person will be in excellent health if the individual is inactive or obese. This becomes a greater concern when health practitioners accept obesity as normative for these adults because they have a disability. By not addressing the issue of obesity and sedentary lifestyles, practitioners are inadvertently making it more likely for these adults to be at greater risk for future health problems (Bodde et al., 2013; CDC, 2011; Janicki et al., 2002; USDHHS, 2008; WHO, 2014).

Santos et al. (2012) found that for older adults, more time spent engaging in sedentary activities resulted in less functional fitness for the individual. Functional fitness is the ability to engage independently in daily living activities without fatigue or tiredness. As adults age and inactivity increases, independence for these adults decrease (Hilgenkamp et al., 2010; Messent, Cook \& Long, 1998; Temple et al., 2006). The more an adult can do independently, the more activities and opportunities he or she has to increase his or her quality of life (Hilgenkamp et al., 2010, 2011; Mendonca et al., 2010). Important components of this fitness involve muscle strength and endurance, balance, and cardiorespiratory endurance (Hilgenkamp et al., 2010). These targeted areas have been the focus for interventions involving adults with ID because jobs for individuals with ID are more dependent on physical than cognitive abilities (Croce \& Horvat,1992; Crowley et al., 2011; Dodd \& Shield, 2005; Rimmer et al., 1996; Shield et al., 2013; Shield \& Taylor, 2010).

Spanos et al. (2013) commented on the inconsistency and limited number of interventions used to address physical activity in adults with disabilities. Lante et al. (2011) and Robertson et al. (2000) claimed that the most effective way to improve the health of individuals with disabilities is to increase their levels of MVPA. Finlayson et al. (2009) discovered that of adults with ID whom 
engaged in physical activity, $43 \%$ engaged in walking, which was the most common behavior across all levels of MVPA. Effective interventions to increase MVPA with this population need to be developed and evaluated.

Engaging in exercise can be challenging for individuals with ID because exercising might not be reinforced, resources to exercise are limited or unaddressed, and barriers for exercising may be inhibiting such behaviors (Heller, Hsieh, \& Rimmer, 2004; Stanish, Temple, \& Frey,2006). Therefore, interventions should focus on creating appropriate contexts for exercise to occur regularly, arranging establishing operations for reinforcers that might maintain physical activity, and reinforcing exercise when it occurs.

The limited research on exercise for adults with ID has varying outcomes. Stanish and Draheim (2005) examined walking by adults with ID across one week. They reported that about $64 \%$ of the participants engaged in MVPA five times throughout the week, however only $17 \%$ met the recommended 30 min of MVPA for these 5 days. Endurance and duration is crucial to achieve the health benefits accompanying physical activity. Moss (2009) implemented a walking program for adults with ID at risk for coronary heart disease. Participants walked a 400-m loop for $20 \mathrm{~min}$ continuously, increasing to $30 \mathrm{~min}$ by 12 weeks. Adherence to this program was only $47 \%$ and participants who attended $50-70 \%$ of the sessions had the greatest increase in fitness levels. The individuals who attended daily and walked more laps had healthier outcomes from the start of the study, so the impact of this study was not as noticeable as it was for those whom were sedentary from the beginning. This study highlighted that any activity for sedentary individuals can be beneficial but consistently engaging in activity is essential. Todd and Reid (2006) utilized self-monitoring, verbal cueing, encouragement, and edible reinforcement to increase distance snowshoed, walked, and jogged for individuals diagnosed with autism. Stickers were used to track the number of laps and edible and social reinforcers were delivered contingent on completing laps. The number of laps 
required to earn an edible was increased across phases to fade out the edible reinforcers. This study revealed that the multicomponent intervention resulted in an increase in laps for all participants.

A few studies have implemented token reinforcement to increase duration or frequency of a specified exercise activity for individuals with ID (Alstot, 2012; Bennett et al., 1989; Croce\& Horvat, 1992; Todd \& Reid, 2006). Bennett et al. (1989) administered tokens for pedaling a predetermined number of rotations on a stationary bike; tokens were exchanged later for backup reinforcers. Time on task increased and variability in exercise behavior decreased with the onset of the intervention. Furthermore, when the token economy was withdrawn, time on task dropped to baseline levels, highlighting the control of the intervention. This study only explored physical activity in 15-min increments. Croce and Horvat (1992) used tokens to reward participants for meeting or exceeding the duration or frequency of activity from the previous session. The participants were encouraged to run/walk/cycle for as long as they could during treatment while maintaining their heart rate in preestablished heart-rate zones. Social reinforcement in the form of encouragement or feedback was provided concurrently during exercise and as feedback at the end of each session. One token was given at the end of the session contingent on meeting the duration or frequency of an exercise from the previous session, and an additional token for every $30 \mathrm{~s}$ longer, quarter lap further, or repetition more from the previous session. Tokens were exchanged or accumulated weekly. This study showed increases in exercise for the participants during intervention, with a downward trend towards baseline levels during the retention phase.

Few studies have explored the use of tokens to increase physical activity (Alstot, 2012;Bennett et al., 1989; Croce \& Horvat, 1992; Todd \& Reid, 2006). This user-friendly, easilyimplemented intervention showed promising results for increasing physical activity. However,these studies were limited in that they were conducted in places that the subjects did not spend time on a daily basis (such as work or home), potentially limiting their ability to exercise by requiring a greater 
response effort for caregivers to drive the individuals to and from the exercise locations. Preference assessments were also not described in the methods of these studies, which could have limited the individuals' contact with their most potent reinforcers contingent on exercise.

The current study examined a token reinforcement intervention implemented at individuals' worksites to reduce response effort for participation and obstacles to implementation. Providing a walking program at a location where individuals spend time on adaily basis increases the likelihood that the intervention will be implemented efficiently andcarried out with high fidelity as part of a daily routine. Furthermore, creating an environmentwith frequent opportunities to access backup reinforcers, identified though a preferenceassessment, contingent on walking may promote program adherence and success. Consequently,the purpose of this study was to examine whether token reinforcement will increase distancewalked for adults with ID attending an adult day training center (ADT). 


\section{Method}

\section{Participants}

Five men, ages 34 to 67, participated in the study. The participants were diagnosed with mild to moderate intellectual disability and had no physical disabilities that prevented walking. John was 67 years old, diagnosed with moderate intellectual disabilities, was obese and diabetic. Paul was 53 years old and had a diagnosis of mild intellectual disabilities. He was overweight, diabetic and had a doctor's recommendation to engage in physical activity each day. Jerry was 37 years old and had a diagnosis of mild intellectual disabilities. He was obese and smokedcigars during breaks while walking. Elton was 46 years old and had a diagnosis of mildintellectual disabilities. Elton was normal weight and had previously participated in a walkinggroup. Frank was 34 years old and had a diagnosis of moderate intellectual disabilities. He wasunderweight and worked two mornings out of the week. All participants signed consent forms(see Appendix A). The participant answered the seven questions in the Physical ActivityReadiness Questionnaire (PAR-Q) (Thomas \& Shepard, 1992) to ascertain that no participanthad health risks associated with engaging in walking. No participant answered yes to any of thequestions, indicating that exercising would not be detrimental to his health. The participantswere told they could leave the study at any time.

\section{Setting}

This study was conducted at one adult day training (ADT) center in Florida. Adult day training centers are places where adults with varying disabilities learn functional and occupa- tional skills. Staff members supervise the adults working on skills and activities that enhance their quality of life. After time spent in the center each day, the adults return to their residences. 
The ADT center used in this study had a staff to client ratio of $1: 4$. The individuals arrived by vans from their residences at 8:30 a.m. and left at 2:30 p.m. All the individuals that attend the ADT were divided into groups, or "crews," and had a consistent, daily routine with their crew members. Their activities include working in the community, going on outings, or cleaning around the ADT.

\section{Materials}

Cones were used to mark a 50-m loop around which the participants walked. The loop was in the same location for all sessions, in an outside, covered corridor where staff had constant supervision. One personalized gift bag was hung for each participant on the fence next to one end of the loop so he could place the tokens in his bag after completing each lap. A data sheet was used by the observers to tally the number of laps completed within the hour (see AppendixB). The bags, tokens, and reinforcers were brought to and from each session by the researcher. Examples of reinforcers earned throughout the study included: Gatorade, diet beverages,Pokémon cards, CD's, novels, professional wrestling paraphernalia, healthy snack bars, stringbracelets, water bottle, coffee mug, sensory balls, and playing cards. An alarm on a phone was set to alert the participants when the hour walking limit was complete.

\section{Target Behaviors and Data Collection}

The primary dependent measure was the number of 50-m loops walked in an hour, measured by the researchers on the data sheet and by the number of tokens placed in the bags after each session. A lap was defined as walking from the end of the loop where the bags were hung to the opposite end, going around the cone at the opposite end, and returning to the starting point. During intervention phases, participants also placed a token in the individualized bag upon completing a lap. If the participant stopped walking after completing over half of a lap, the lap was scored as a completed lap and the participant placed the token in his bag. A zero for the day resulted 
when participants had the opportunity but refused. A day without a data point indicated that the participant was absent from the site or was working with his crew, and thus had no opportunity to walk. A secondary dependent measure was frequency of breaks within the hour, tallied on the same data sheet. Throughout all phases in the study, the researcher and independent observer used data sheets to track number of laps walked within the session.

\section{Interobserver Agreement and Treatment Integrity}

For $38.1 \%$ of the sessions, both the researcher and an independent observer recorded the number of laps and breaks on a data sheet. At the end of the session, interobserver agreement (IOA) was calculated by dividing the lower number of laps by the higher number of laps multiplied by 100 for each participant to obtain a percentage agreement between the researcher and the second observer. The independent observers were graduate research assistants. IOA for John was $99.6 \%$ for laps and $95.1 \%$ for breaks. IOA for Paul was $99.6 \%$ for laps and $97.3 \%$ for breaks. IOA for Jerry was $100 \%$ for laps and $98.4 \%$ for breaks. IOA for Elton was $99.8 \%$ forlaps and $100 \%$ breaks. IOA for Frank was $99.9 \%$ for laps and $100 \%$ for breaks.

Treatment integrity was recorded at the end of each session to assure that after receiving the token from the researcher, the participants placed the tokens in their bags and that the number of tokens in the bags equaled the number of laps tallied on the data sheet that theresearchers used. This served as a permanent product measure of the researcher's behavior.Treatment integrity was calculated by for each participant by dividing the lower number of laps by the higher number of laps to obtain a percentage agreement between the laps tallied by the researcher and the tokens in the bag. Treatment integrity was $100 \%$ for all participants.

\section{Design}

An $A B A B$ design was used to evaluate the effectiveness of token reinforcement forincreasing distance walked. 


\section{Procedures}

Staff/participant meeting. A meeting was held with the clinical director and the research assistants to describe the study and their roles as independent observers. The researcher and agency agreed that the walking program would occur from 9 a.m. to 10 a.m. each weekday. The investigator discussed the resources that were available at the ADT for the development ofthe intervention. Establishing participants' individual privileges helped determine potential backup reinforcers included in the preference assessment. The researcher was introduced to the participants, the study was described to the participants, the PAR-Q was completed, consent was obtained, and the schedule was given to the participants so they knew when they had the opportunity to walk.

Baseline. Data collection began one week after meeting the participants. Each session,the researcher arrived at least 10 min early to meet the staff member required by the site to be with the walking group, gather the participants, and set up the walking loop. Once all of the participants were together, the researcher asked, "who wants to walk today?" The participants that said they wanted to walk followed the staff member and researcher to the walking loop. Only the participants in this study were permitted to walk the loop. A cone was placed at each end ( $25 \mathrm{~m}$ apart) to mark off the walking loop. Once the loop was set up and it was 9 a.m., the researcher said, "you guys can start walking now!" Sessions lasted for one hour or until the participant stated he was done walking for the day. Participants were allowed to take a breakfrom walking anytime during the session. A break was tallied anytime the participant walked offthe walking loop for more than $10 \mathrm{~s}$ and if the participant was at the loop when the researchertold the participants to begin walking and the participant waited for more than $10 \mathrm{~s}$ to startwalking. No tokens or praise were delivered for walking. The researcher stayed at the start of theloop and stated aloud the lap number each participant started (e.g., This is your third lap) in aneutral affect. The researcher tallied the number of laps walked and breaks taken by eachparticipant on the data sheet. 
Throughout this phase, prior to conducting the preference assessments, the researcher interviewed the staff and participants to identify what tangibles or edibles the participants preferred (see Appendix C).

Preference assessment. After baseline data were stable, the preference assessment was conducted on the next scheduled day. A multiple stimulus preference assessment without replacement was conducted using the stimuli identified by the staff and participants in the interviews. The tangibles and edibles identified by the participants and staff were placed in front of each participant in an array, and he chose one item. That item was removed and in the next trial the array included the remaining choices and the participant chose one item. This was repeated until only one item was left. This assessment was repeated three times for each participant, with at least 5 min between each assessment. A hierarchy of preference for the itemswas determined from the result of these assessments. Once potential reinforcers were identified, the token exchange rate was determined based on the preference hierarchy. The more preferredthe item was, the more tokens it cost. The token exchange rate was based on each individual'sbaseline levels of walking to ensure each participant had a similar opportunity to earn each reinforcer. The exchange rate for the most preferred item was the average number of laps walked during baseline multiplied by five; the exchange rate for the least preferred potential reinforcerwas the baseline average for laps walked. Appendix D shows the token exchange rates. The potential reinforcers that they could earn during the intervention phase were made unavailable tothe participants at the ADT during the intervention phase to create an establishing operation.After each participant completed the preference assessments, the researcher brought the participants to the start of the loop and showed the participants their individualized bags. The researcher then demonstrated a lap: starting at the cone, walking to the other side of the loop, around the come and back to the start, placing a token in the individualized bag. Each 
participantrehearsed a lap by walking around the loop and placing his token in his bag. All participantsexecuted this correctly on their first attempt.

Token reinforcement. During the token phase, the participants earned tokens they could exchange for backup reinforcers identified through the preference assessments. The start of each session was identical to baseline, except that the researcher told the participants that they would be given a token after completing each lap and that the tokens could be exchanged for their preferred items or edibles at the end of the session or be saved for a later session. After this discussion, the walking program began with the announcement of, "you guys can start walking now!” The participants had an individualized bag hanging from the fence outlining the loop. The participants all started at the opening of the corridor, walked to the opposite side of the loop, turned around the outside of the cone, walked back to the start and were given a token to place in their bags. The participants walked back and forth as much as they decided to within the hour. If the participant stated he wanted a break, he would exit the loop and come back whenever he was ready. The researcher and staff member provided social support in the form of encouraging statements (e.g., “Great job! You are walking for [reinforcer]! Keep up the hard work!”) for $5 \mathrm{~s}$ after placing a token in the bag and every other time the participant reached the opposite side of the loop. The start of each session began with $10 \mathrm{~s}$ of social support as well. At the end of the hour, the researcher and staff member counted the tokens, told the participants how many laps they walked, and told them what they earned. The participants chose to exchange or accumulate the tokens earned from walking. When the tokens were exchanged for the backup reinforcers, the tokens were returned to the researcher. 


\section{Social Validity}

A questionnaire was given to participants and the staff at the ADT to assess their opinions of the walking program (see Appendix E and F). The questionnaires consisted of questions about activity levels before and after participating in the program and on the program's acceptability. 


\section{Results}

\section{Walking}

Figure 1 depicts laps walked per session across all phases for all participants. The triangles on the graph indicate days in which the participants arrived late to the ADT. The first Token Reinforcement phase resulted in a noticeable increase in laps for four out of five participants (John, Paul, Jerry, and Frank). Upon the return to Baseline, the laps decreased for all five participants (to around Baseline levels for four of the five, and to levels lower than the first BL on a decreasing trend for Elton). Once Token Reinforcement was implemented again, all five participants substantially increased their laps to levels around those of the first intervention phase or higher.

During Baseline, John walked a mean of 12.5 laps per session (ranging from 0-16). During the first Token Reinforcement phase, John's mean number of laps per session increased to 24.4 (ranging from 21-28). The return to Baseline resulted in an immediate decrease to a mean of 16.5 (ranging from 14-18). The final Token Reinforcement phase resulted in an immediate increase to a mean of 31 (in an increasing trend ranging from 18-37). John walked the most laps in a session during the last phase of the study.

In the second panel, Paul walked a mean of 16.7 laps per session (ranging from 0-43) during baseline. During the first Token Reinforcement phase, Paul's mean increased to 56 (ranging from 1070). The return to Baseline resulted in an immediate decrease to a mean of 8.5

(ranging from 0-23). The final Token Reinforcement phase resulted in an immediate increase to a mean of 49.3 (ranging from 0-66) with an increasing trend. Paul sustained an injury unrelated to the study, which prevented him from participating in the rest of the study. 
In the third panel, Jerry walked a mean of 6.7 laps per session (ranging from 0-32) in baseline. During the first Token Reinforcement phase, Jerry's mean increased to 39.2 (ranging from 0-53). The return to Baseline resulted in an immediate decrease to a mean of 15.The final Token Reinforcement phase resulted in an immediate increase to a mean of 39.3 (in an increasing trend ranging from 10-60). Jerry walked the most of laps in a session during the last phase of the study.

In the fourth panel, Elton walked a mean of 63.8 laps per session (ranging from 55-74) in baseline. During the first Token Reinforcement phase, Elton's mean increased to 71.4 (ranging from 59-79). The return to Baseline resulted in a decrease to a mean of 58.7 (ranging from 30-78). The final Token Reinforcement phase resulted in an immediate increase to a mean of 70.8 (in an increasing trend ranging from 60-80). Elton walked the most laps in a session during the last phase of the study.

In the last panel, Frank walked a mean of 20.2 laps per session (ranging from 0-59) in Baseline. During the first Token Reinforcement phase Frank's mean increased to 77.3 (ranging from 20-94). The return to Baseline resulted in an immediate decrease to a mean of 25.75(ranging from 072). The final Token Reinforcement phase resulted in an immediate increase toa mean of 71.8 (in an increasing trend ranging from $0-92$ ).

\section{Social Validity Questionnaire}

Participants and a staff member completed the social validity questionnaire on the last day of the study (see Appendix E and F). Questions were scored on a 5 point rating scale; strongly disagree (1) to strongly agree (5). The participants' mean score for question 1 was 4.8 (ranging from 4 to 5), question 2 was 4.6 (ranging from 4 to 5), question 3 was 4.8 (ranging from 4 to 5), and question 4 was 4.6 (ranging from 4 to 5). The staff member's scores on question 1 through 4 were $5,4,5$, and 5 respectively. 


\section{Preference Assessment}

Preference assessment results are in table 1. Items selected in the preference assessment, percentage of reinforcers chosen within the token reinforcement phases and total cost ofreinforcers per participant are included in the table. 


\section{Discussion}

This study demonstrated that a token reinforcement program increased distanced walked for adults with intellectual disabilities. Across all participants, the baseline phases had the fewest laps walked per session and the intervention phases had the highest number of laps walked per session. For three of the five participants (John, Jerry, and Elton) the highest number of laps walked per session occurred in the second Token Reinforcement phase. There are a few overlapping data points between baseline and intervention for each participant attesting to the daily variability inherent in physical activity. For four of the five participants (John, Paul, Elton, and Frank) there is clear differentiation between baseline and intervention phases. Sessions in which participants were late typically resulted in fewer laps walked.

John had a stable baseline and an immediate increase during token reinforcement phases, with an increasing trend in the last phase of the study. Staff members particularly commented about his increases in physical activity throughout this study, as he was considered one of theleast active adults at the ADT.

Paul sustained an injury unrelated to the study after the 27 th session and was unable to continue. With the implementation of token reinforcement, Paul immediately walked more laps and there was a slightly increasing trend until the end of the phase where his data stabilized. In the return to baseline phase laps drastically dropped and remained low. An instant increase in level occurred in the last token reinforcement phase, with a level similar to the first token phase.

Jerry had clear differentiations between baseline and treatment phases, with immediate increases in laps when tokens were introduced. He was very rigid in his behavior, walking only the 
number necessary for each reinforcer. The second Token Reinforcement phase shows the variability in the number of laps he decided to walk to earn various reinforcers.

Elton's walking distance did not have much differentiation across phases throughout the study. Although he had a decreasing trend in the second baseline, his data were stable throughout all other phases in the study. Elton attended each walking session and was the only participant that always walked at least 30 laps per session. He also had the highest number of laps walked throughout the study.

Frank walked the highest number of laps across all participants in a given day; his highest day was 94 laps (about 3 miles) in an hour. He missed the most sessions of any participant, likely attributed to his "crew" working Tuesday and Thursday mornings. Days in which he was late resulted in fewer laps walked. He lost three pounds during this study. Frank and Elton raced each other most mornings, creating a competition that likely increased the number of laps for each of them.

These results are consistent with research from Bennett et al. (1989) Croce and Horvat (1992), and Todd and Reid (2006) indicating that providing reinforcers contingent on exercising in a token economy increases exercise for adults with intellectual disabilities. The current study adds to research by having longer exercise sessions, including a preference assessment to identify individual reinforcers, and promoting physical activity at an ADT, the work site where the participants attended daily. Promoting physical activity at a place where individuals attend daily increases the accessibility and convenience of exercising. Having planned and structured activities increases the likelihood of an individual's engagement in the activity, thus reducing the 
response effort to engage in exercise. Making exercise accessible, convenient and planned increases the probability of it occurring.

Unlike Todd and Reid (2006), this study found a functional relationship between token reinforcement and walking as demonstrated in the ABAB design. In Todd and Reid the intervention consisted of token reinforcement along with self-monitoring, cuing, and encouragement and there was no reversal. In this study the exercise session was longer (1 hr) compared to previous research (Bennett et al., 1989; Croce \& Horvat, 1992; Moss, 2009; Todd \& Reid, 2012). Bennett et al. (1989) conducted sessions that lasted for $15 \mathrm{~min}$, Croce and Horvat (1992) had sessions that lasted up to 40 min, Moss (2009) had sessions that lasted up to 30 min, and Todd and Reid (2012) had 30-min sessions.

Results from the social validity questionnaire from the participants revealed they all enjoyed the walking program. Four out of five participants strongly agree that they are more active now after the walking program than they were before the program started. Three out of the five participants strongly agree that they will continue walking now that the program is completed. Participants also indicated their favorite things about the program included staying healthy, weight loss, earning individual rewards, and gaining endurance. Staff strongly agreed that the program was feasible, participants became more active, and that the reinforcement was effective in increasing exercise for the participants.

The preference assessment was effective in identifying reinforcers for each participant. John and Paul chose more immediate forms of reinforcement by selecting their lowest preferred items compared to accumulating tokens for their highest preferred items. Jerry chose a variety of 
reinforcers throughout both phases, selecting both his highest and lowest preferred items. He cycled through his reinforcers, selecting highest preferred items back to back, then switching to lower preferred items and then back to highest preferred items again. This cycle occurred across both token reinforcement phases. Elton and Frank selected their highest reinforcers throughout the study. They accumulated their tokens to exchange them for items with higher level of preference. The total cost for each participant's reinforcers ranged from 9 to 53 dollars, totaling 161 dollars. This intervention was cost effective for the 10 -week duration of the study.

Anecdotal reports from staff members at the ADT included the following statements: "I can't believe John and Jerry are walking that much, show me a video!" "It's crazy to see how much they are walking when they have something they are motivated for. This is great for all of them." "This is so good for their health, you know for high blood pressure and diabetes. Anyone here could benefit from it." Staff also commented about weight loss for four of the five participants (John, Paul, Jerry, and Elton). Anecdotal reports from participants included the following statements: "I feel as healthy as a horse!" "I'm as fast as blue lightening," "Look how fast I'm walking, I'm going to set a new record!" "He can't catch me! I'm too fast." "I'm losing weight too! My tummy is going down. I feel good."

Although the token reinforcement program clearly increased walking for the participants, a number of factors appeared to affect the participants' walking throughout the course of the study. One factor was that competing contingencies affected attendance during the walking program for one participant. Frank's crew worked two mornings each week across all phases in the study. Monetary compensation for working rightfully competed with exercise in themornings for Frank. That he 
chose work over walking on days when work was available seemsto be a good decision as the goal of the ADT was to promote meaningful work. The implicationfor future research on exercise is that the exercise program should be made available at multiple times to accommodate work schedules. Other attendance issues that affected the number of laps the participants walked included participants attending doctor appointments or arriving late to the ADT due to transportation issues. Because staff at the ADT picked up the participants from their residences, some mornings participants were late due to staff arriving late or other individuals in their homes refusing to leave. Another factor that may have influenced walking is that the walking loop was outside, under a covered hallway at the ADT, so weather conditions (cold or hot) could have been a factor in how much the participants walked. The participants'choice of clothing may have also influenced their walking. On many occasions individuals did not dress appropriately for physical activity (i.e., wearing steel toe boots with no socks, shorts in cold weather, jeans and dress shirts compared to workout clothes, pants too big with no belt) and on some occasions painful conditions due to walking occurred and influenced the participants'decision to walk (i.e., blisters, sore muscles). Some participants were active on the weekends and evenings outside of this study. Anecdotal reports from participants indicated muscle soreness due to the outings (i.e., attending dance parties, monster truck rallies, And fairs) influenced their willingness to walk or walk as far as usual.

Besides the health benefits associated with physical activity, other potential benefits of increasing physical activity were shown by Croce and Horvat (1992) and Bennett et al. (1989) including increased work activity and time on task. These studies suggest that increased walking may be beneficial for work productivity even when a portion of the workday is used for walking. The 
implication is that walking or other exercise programs can be and perhaps should be conducted at work sites for adults with disabilities. Future research should also look into analyzing token economies with other exercise behaviors or in other settings. Although this study was conducted in one particular type of work setting, replicating this research with individuals in residential settings (e.g., in-patient settings, apartments, or in natural homes), school settings, or other work settings would extend our knowledge about the effectiveness of token reinforcement for increasing exercise among individuals with intellectual disabilities. Also, studying staff-implemented physical activity programs in this and other settings would provide information about the generalizability and social validity of activity-promotion programs. Although staff in the ADT positively evaluated the intervention conducted by the researchers during the workday, it is not clear whether the intervention could be sustained by staff if they were responsible for its implementation. As this study utilized a preference assessment to determine individual reinforcers for participants, it is unclear whether it was more successful or effective compared to other studies using rewards not identified with a preference assessment. Future research should focus on determining which of these approaches is more effective and efficient to increase exercise behaviors. More research evaluating a variety of exercisepromotion interventions, in a variety of settings, for adults with varying disabilities isnecessary. 


\section{Tables and Figures}

\section{Table 1}

Items selected in the preference assessment, percentages of reinforcers chosen, and total cost ofreinforcers across participants

\begin{tabular}{|c|c|c|c|c|}
\hline Participants & $\begin{array}{l}\text { Items chosen in } \\
\text { Preference } \\
\text { Assessment with } \\
\text { Token Exchange } \\
\text { Rates }\end{array}$ & $\begin{array}{l}\text { Selection \%of } \\
\text { Reinforcers in } \\
\text { Token Phase } 1\end{array}$ & $\begin{array}{l}\text { Selection \%of } \\
\text { Reinforcers in } \\
\text { Token Phase } 2\end{array}$ & $\begin{array}{l}\text { Total Cost of } \\
\text { Reinforcers }\end{array}$ \\
\hline John & $\begin{array}{l}\text { Book }(75,75) \\
\text { CD }(65,65) \\
\text { Nutella Sticks } \\
(60,50) \\
\text { Uno }(45,45) \\
\text { Word Search }(35, \\
35) \\
\text { Diet Soda }(20,25) \\
\text { Gatorade }(15,25)\end{array}$ & $\begin{array}{l}\text { Diet Soda: } 75 \% \\
\text { Gatorade: } 16.7 \% \\
\text { Uno: } 8.3 \%\end{array}$ & $\begin{array}{l}\text { Gatorade: } 96 \% \\
\text { Diet Soda: } 4 \%\end{array}$ & $\$ 29$ \\
\hline Paul & $\begin{array}{l}\text { CD }(125,135) \\
\text { Coffee Mug }(100, \\
110) \\
\text { Diet Soda }(75,70) \\
\text { Gatorade }(25,50) \\
\text { Gatorade Chews } \\
(50,25)\end{array}$ & $\begin{array}{l}\text { Gatorade: } 81.8 \% \\
\text { CD: } 9 \% \\
\text { Gatorade Chews: } \\
9 \%\end{array}$ & $\begin{array}{l}\text { Gatorade: } 75 \% \\
\text { Gatorade Chews: } \\
25 \%\end{array}$ & $\$ 10$ \\
\hline
\end{tabular}


Table 1 Continued

\begin{tabular}{|c|c|c|c|c|}
\hline Elton & $\begin{array}{l}\text { Book }(320,320) \\
\text { Water Bottle } \\
(256,250) \\
\text { Light up ball } \\
(192,200) \\
\text { Word search } \\
(128,130) \\
\text { Flavored Water } \\
(64, \\
65)\end{array}$ & $\begin{array}{l}\text { Book: } 50 \% \\
\text { Ball: } 50 \%\end{array}$ & Book: 100\% & $\$ 52$ \\
\hline Frank & $\begin{array}{l}\text { CD }(125,320) \\
\text { Book }(100,300) \\
\text { WWE (Token } \\
\text { Phase2 only, } \\
200) \\
\text { Water Bottle } \\
(120,200) \\
\text { Gatorade }(75, \\
175) \\
\text { Light up Ball } \\
(50,100) \\
\text { Cards }(25,65)\end{array}$ & $\begin{array}{l}\text { Book: } 50 \% \\
\text { CD: } 50 \%\end{array}$ & $\begin{array}{l}\text { Book: } 16.7 \% \\
\text { WWE: } 50 \% \\
\text { Water } \\
\text { bottle: } 16.7 \% \\
\text { Light up } \\
\text { ball:16.7\% }\end{array}$ & $\$ 40$ \\
\hline
\end{tabular}




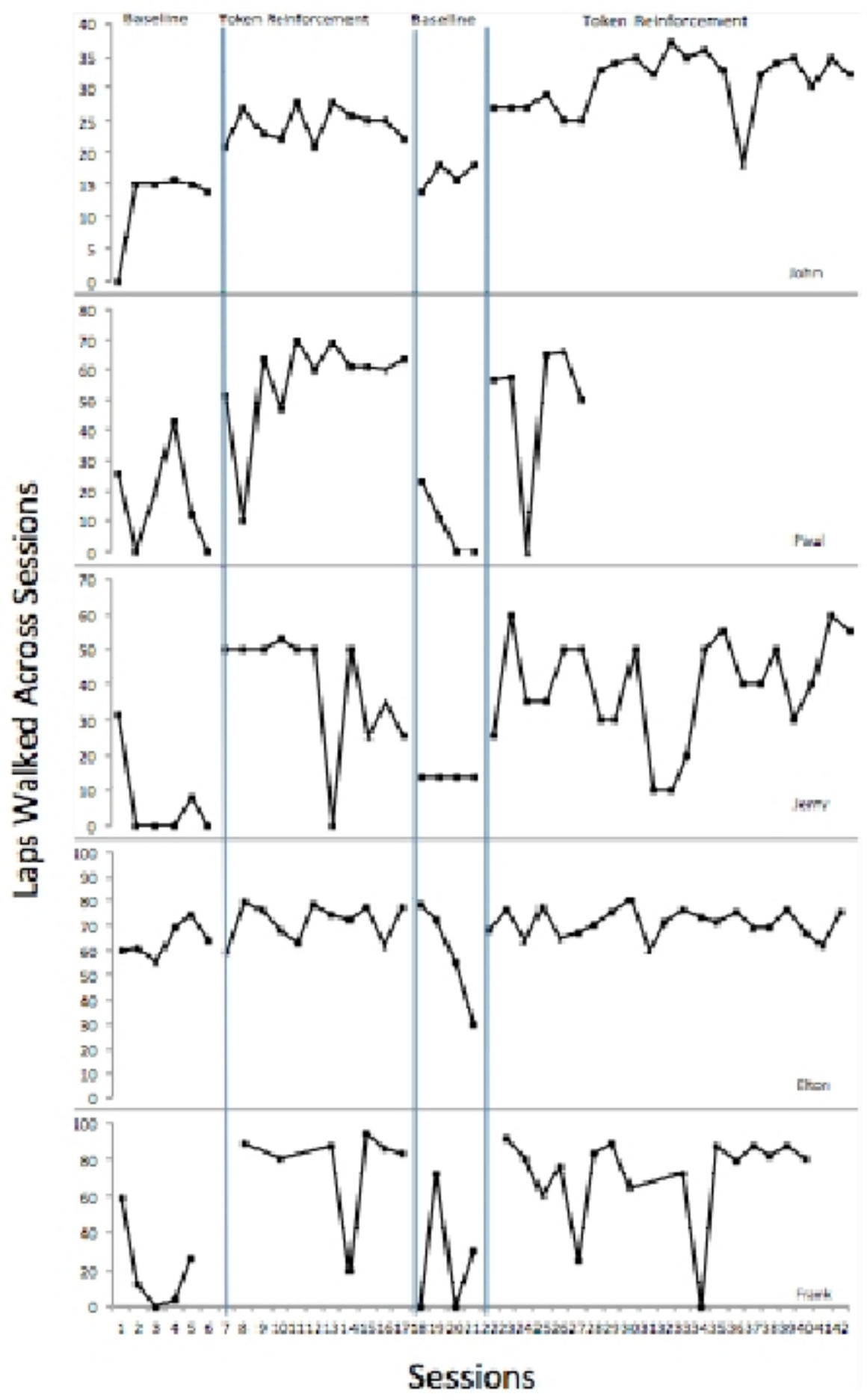

Figure 1. Laps walked per session across participants. 


\section{References}

Alstot, A. E. (2012). The effects of a peer-administered token reinforcement on jump rope behaviors in elementary physical education students. Journal of Teaching in PhysicalEducation, 31, 261-278.

Bazzano, A. T., Zeldin, A. S., Shihady Diab, I. R., Garro, N. M., Allevato, N. A., \& Lehrer, D.(2009). The healthy lifestyle change program: A pilot of community-based healthpromotion intervention for adults with developmental disabilities. American Journal ofPreventive Medicine, 37, 201-208. doi:10.1016/j.amepre.2009.08.005

Bodde, A. E., Seo, D. C., Frey, G. C., Van Puymbroeck, M., \& Lohrmann, D. K. (2013).Correlates of moderate-to-vigorous physical activity participation in adults withintellectual disabilities. Health Promotion Practice, 14, 663-670. doi:10.1177/1524839912462395

Bennett, F., Eisenman, P., French, R., Henderson, H., \& Shultz, B. (1989). The effect of a tokeneconomy on the exercise behavior of individuals with Down Syndrome. AdaptedPhysical Activity Quarterly, 6, 230-246.

Carmeli, E., Kessel, S., Coleman, R., \& Ayalon, M. (2002). Effects of a treadmill walkingprogram on muscle strength and balance in elderly people with Down Syndrome. Journalof Gerontology, 57, 106-110. doi: 10.1093/gerona/57.2.M106

Caspersen, C. J., Powell, K.E., \& Christenson, G. M. (1985). Physical activity, exercise, andphysical fitness: Definitions and distinctions for health-related research. Public Health Reports, 100, 126-130. 
Centers for Disease Control and Prevention. (2014). Physical activity for everyone: How muchphysical activity do older adults need? Retrieved from http://www.cdc.gov/physicalactivity/everyone/guidelines/olderadults.html

Conn, V. S., Hafdahl, A. R., \& Mehr, D. R. (2001). Interventions to increase physical activity among healthy adults: Meta analysis of outcomes. Research and Practice, 101, 751-759. doi: 10.2105/AJPH.2010.194381

Croce, R. \& Horvat, M. (1992). Effects of reinforcement based exercise on fitness and work productivity in adults with mental retardation. Adapted Physical Activity Quarterly, 9,148178.

Dodd, K. J. \& Shields, N. (2005). A systematic review of the outcomes of cardiovascular exercise programs for people with down syndrome. Archives of Physical Medicine andRehabilitation, 10, 2051-2058. DOI: 10.1016/j.apmr.2005.06.003

Fernhall, B., Pitetti, K. H., Rimmer, J. H., McCubbin, J. A., Rintala, P., Millar, A. L., .. Burkett,L. N. (1996). Cardiorespiratory capacity of individuals with mental retardation includingdowns syndrome. Medicine \& Science in Sports and Exercise, 28, 366-371. DOI:10.1097/00005768199603000-00012

Finlayson, J., Jackson, A., Cooper, S. A., Morrison, J., Melville, C., Smiley, E., ... Mantry, D.(2009). Understanding predictors of low physical activity in adults with intellectualdisability. Journal of Applied Research in Intellectual Disabilities, 22, 236-247. DOI:10.1111/j.14683148.2008.00433.x

Finlayson, J., Turner, A., \& Granat, M. H. (2011). Measuring the actual levels and patterns of physical activity/inactivity of adults with intellectual disabilities. Journal of AppliedResearch in Intellectual Disabilities, 24, 508-517. DOI: 10.1111/j.1468-3148.2011.00633.x 
Hawkins, B. L., Stegall, J. B., Weber, M. F., \& Ryan, J. B. (2012). The influence of a yoga exercise program for young adults with intellectual disabilities. International Journal ofYoga, 2, 151156. doi:10.4103/0973-6131.98244

Heller, T., Fisher, D., Marks, B., \& Hsieh, K. (2014). Interventions to promote health: crossingnetworks of intellectual and developmental disabilities and aging. Disability and HealthJournal, 7, 24-32. doi:10.1016/j.dhjo.2013.06.001

Heller, T., Hsieh, K., \& Rimmer, J. H. (2004). Attitudinal and psychosocial outcomes of a fitness and health education program on adults with Down Syndrome. American Journal of Mental Retardation, 109, 175-185. doi: 10.1352/0895-8017(2004)109<175:AAPOOA>2.0.CO;2

Hilgenkamp, T.I., Wijck, R., \& Evenhuis, H. M. (2010). Physical fitness in older people with IDConcept and measuring instruments: A review. Research in Developmental Disabilities, 31, 1027-1038. doi:10.1016/j.ridd.2010.04.012

Hilgenkamp, T. I., Wijck, R., \& Evenhuis, H. M. (2011). (Instrumental) activities of daily livingin older adults with intellectual disabilities. Research in Developmental Disabilities, 32,19771987. doi:10.1016/j.ridd.2011.04.003

Hilgenkamp, T. I., Reis, D., Wijck, R., \& Evenhuis, H. M. (2012). Physical activity levels inolder adults with intellectual disabilities are extremely low. Research in DevelopmentalDisabilities, 33, 477-483. doi:10.1016/j.ridd.2011.10.011

Hsieh, K., Rimmer, J. H., \& Heller, T. (2013). Obesity and associated factors in adults withintellectual disabilities. Journal of Intellectual Disability Research, 20, 1-13. DOI:10.1111/jir.12100 
Janicki, M. P., Davidson, P. W., Henderson, C. M., McCallion, P., Taets, J. D., Force, L. T., ...Ladrigan, P. M. (2002). Health characteristics and health services utilizations in olderadults with intellectual disability living in community residences. Journal of IntellectualDisability Research, 46, 287-298. DOI: 10.1046/j.1365-2788.2002.00385.x

King, A. C., Rejeski, J., \& Buchner, D. M. (1998). Physical activity interventions targeting olderadults- A critical review and recommendations. Preventative Medicine, 15, 316333.doi:10.1016/S0749-3797(98)00085-3

Martin Ginis, K. A., Nigg, C. R., \& Smith, A. L. (2013). Peer-delivered physical activity interventions: an overlooked opportunity for physical activity promotion.

TranslationalBehavior Medicine, 3, 434-443. DOI 10.1007/s13142-013-0215-2

Melville, C. A., Hamilton, S., Hankey, C. R., Miller, S., \& Boyle, S. (2007). The prevalence and determinants of obesity in adults with intellectual disabilities. Obesity Reviews, 8, 223-230. DOI: $10.1111 /$ j.1467-789X.2006.00296.x

Mendonca, G. V., Pereira, F. D., \& Fernhall, B. (2011). Effects of combined aerobic and resistance exercise training in adults with and without down syndrome. Archive of Physical Medicine and Rehabilitation, 92, 37-45. doi:10.1016/j.apmr.2010.09.015

Moss, S. J. (2009). Changes in coronary heart disease risk profile of adults with intellectual disabilities following a physical activity intervention. Journal of Intellectual DisabilityResearch, 53 (8), 735-744. DOI: 10.1111/j.1365-2788.2009.01187.x

National Center on Health, Physical Activity and Disability. (2011). Developmental disability and fitness. Retrieved from http://www.ncpad.org/104/795/Developmental Disability and Fitness

Peterson, J. J., Janz, K. F., \& Lowe, J. B. (2008). Physical activity among adults with intellectualdisabilities living in community settings. Preventative Medicine, 47, 101-106. 
Rimmer, J. H., Braddock, D., \& Pitetti, K. H. (1996). Research on physical activity anddisability: An emerging national priority. Medicine \& Science in Sports and Exercise, 11,1366-1372. DOI: 10.1097/00005768-199611000-00004

Robertson, J., Emerson, E., Gregory, N., Hatton, C., Turner, S., Kessissoglou, S., \& Hallam, A. (2000). Lifestyle related risk factors for poor health in residential settings for people with intellectual disabilities. Research in Developmental Disabilities, 21, 469-486. doi:10.1016/S0891-4222(00)00053-6

Santos, D. A., Silva, A. M., Baptista, F., Santos, R., Vale, S., Mota, J., \& Sardinha, L. B. (2012). Sedentary behavior and physical activity are independently related to functional fitness in older adults. Experimental Gerontology, 47, 908-912. doi:10.1016/j.exger.2012.07.011

Spanos, D., Melville, C.A., \& Hankey, C. R. (2013). Weight management interventions in adults with intellectual disabilities and obesity: A systematic review of the evidence. Nutritional Journal, 12, 1-16.

Temple, V.A., Anderson, C., \& Walkley, J.W. (2000). Physical activity levels of individuals living in a group home. Journal of Intellectual \& Developmental Disability, 25, 327-341. DOI:10.1080/13668250020019601

Thomas, S., Reading, J., \& Shephard, R. J., (1992). Revision of the physical activity readiness questionnaire (PAR-Q). Canadian Journal of Sport Sciences.

Todd, T., \& Reid, G. (2006). Increasing physical activity in individuals with autism. Focus on Autism and Other Developmental Disabilities, 21, 167-176. doi:10.1177/10883576060210030501

US Department of Health and Human Services (2008). 2008 physical activity guidelines. Retrieved from http://health.gov/paguidelines/guidelines/summar.aspx 
Winter, C.F., Bastiaanse, L. P., Hilgentamp, T. I., Evenhuis, H. M., \& Echteld, M.A. (2012).

Overweight and obesity in older people with intellectual disability. Research in

Developmental Disabilities, 33, 398-405. doi:10.1016/j.ridd.2011.09.022

World Health Organization (2014) Global strategy on diet, physical activity and health. Retrieved from http://www.who.int.dietphysicalactivity/factsheet adults/en/ 
Appendix A:

Consent to Participate 


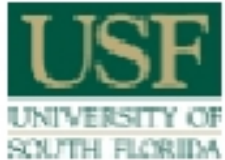

\section{Informed Consent to Participate in Research \\ Information to Consider Before Talking Part in this Research Study}

IRB Stady \# ProA019501

You are being asked to take part in a research study. Research studies include only people who chwose to talke part. This document is calledi an informed consent form. Please read this information carefully and talke your time making your decision. Ask the researcher or staff to discuss this consent form with you, please ask himuher to explain any words or information you do not understand. We encourage you to talk with your family and friends before you decide to talke part in this study. The nature of the study, risks, discomfiorts, and other impartant information about the study are listed belowr.

Plesse tell the srudy investigatar ar study staff if you are taling part in another research sudy.

We are asking you to talke part in a research study called: Using Token Reinforcement to Increase Distance Wallked for Acults with Intellectual Disabilities.

The parson who is in charge of this research study is Haley Krente. This person is called the Principal Investigatar. Howewer, other research staff may be imvolved and can act on behalf of the person in charge. She is being guided in this research by Baymond Miltenberger.

The research will be conducted at Euman Development Center, Inc. (HDC)

Purpose of the study

The purpose of this study is to:

- Find out if delivering tolsens, based ou walling laps, that can be later exchanged for preferred items, will increase the time and distance a participant walks

- This method hss been effective in incressing other forms of physical activity (soveshosing. jogging and weight lifting) for adults with disabilities

- A student is conducting this study for a thesis and will be supervised by a faculty advisor, Raymond Miltenberger

\section{Study Procedures}

If you take part in this study. you will be asked to:

- Spend alsout 2 or 3 monthe in this sudy.

- It will talke place each weekday moming for an hour at HDC 
- Each marning you will have the choice to walls ar not participate

- You aril be asked what items/activities/food you really enjoy at HIDC

- A test will be done to rank these items/activitiesifood

- Tou will be able to earn tokens (Vlelcroed pictures) based on how many laps you walk, and at the end of the session you can decide to keap the tolvens or turn then for your items/activities/fo-ad you identified

- Your IQ skore and diagrosis will be taken from pour medical charts

- If your IQ score is too high or too low you will not be qualified to participate in this scuidy

- You will be asked to fill out a questionnaire ar the end of the study, asking whether ar not you liked participating in the study

\section{Total Number of Partieipants}

About 46 indiwiduals will take part in this study at the Human Development Center. Inc.

Altermatives:

You do sot hane to participate in this research study.

\section{Benefits}

The patential benefirs of participating in this research study include:

- Health benefits associated with increasing physical activity

- Support from peers and researchers while walling

\section{Rislss or Dis comfort}

This research is considered to be minimal risk. That means that the risks with this stady are the same als what you see every day. There are no known other risks to those who take part in this study.

\section{Compensation}

You will receine no payment or other compensation for tnking part in this stady.

Cost

There will be no additional costs to you as a result of baing in this study.

\section{Authorization to Use and Disclose Protected Health Information}

\section{Who will see your health information?}

In this research study. we use your health information to the extent you allow us. We know that this information is private. The federal privacy laws of the Health Insurance Portability \& Accountability Act (HIIPAA) protects your healch information. If you let us use your information we will protect it as required by the law.

Research at The Hum an Development Center, Inc. is conducted with the University of South Florida. By signing this: form, you are allowing The Humsn Development Center. Inc. and the University of 
South Florida to we personal health information collected about you far research purposes. You are also allowing The Human Deviogment Center, Imc, to share your personal health information with individuals ar arganizations other than USF and The Hurman Dovelopment Confer, Inc, who are also involved in the research and listed below.

\section{Who will disclese (share), receive, and/or use your in forma tion?}

To conduct this reseanch. USF and the people and organ izations may use or share your information. They may only use and share your information:

- With the poople and organizations on this list.

- With you

- As allowed by law.

Also, to the people and organizations listed below in the Privacy and Confidentiality section of this document, the folloaring groups of people may also be able to see information about you and may use the information to concuct the resesuch:

- The medical staff that takes care of you and thos e who are part of thie research study:

- The designated peer review committees sach as : Protocol Roviow and Monitoring Conmitwe

Whor else can use and share this information?

Anyone listed above may use advisors in this research and for the purpose of this stady, may share your information with them. If you have questions about who they are, you should ask the Principle Investigator. Pegple who receive your health information for this research study may not be required by the AIIPAA Privacy Rule to protect it and may share your infonmation with ochers without your permission. They can only do sp if peminted by the laws. For efangle, the Irfearch assistants may share your information with others. If the research assistant or others share your information, your information may no longer be protected under the HIIPAA. Priwacy Rule.

How will my information be used?

By signing this form, you are giving your olky to use and/or share your health information as described for any studyiresearch purposes. Your ok ay to use your health information will not be withdrawn unless you say ocherwise it in writing.

\section{As part of this resesrch, USF nay collect, use, and share the following information:}

- Your diagnosis and IQ score record

- All of your past or current medical and other hesilh records beld by The Human Dewelopment Center or ather health care providers. This includes your mental health and genetic information

You can list any information that you do not want us to use or share in the pace below. If you list nothing here, we can use and sbare all of the information listed above for this research but for nothing else.

For the Research Participant (You) to complete:

I am asking USF and the researchers not to inchude, use, or share the following health information in this research (if blank, then no information will be excluded)c

\section{Your Rights:}


You can refuse to sign this form. If you do not sign this form you will not be able to take part in this Jesesrch study and will not be able to receive the trestunent plan. Your besith care cutside of this study and benefits will not change.

\section{How Do. I Withdraw Permission to Use My Informa tion?}

You can cancel this form at any time by sending a letter saying you wish to withdraw your olky to use your health information in the reseanch. If you take back your olay.

- You will not be a participant in this research study.

- We will stop collecting nex information about your

- We will use the infommation collected prior to you canceling This information may already have been used or shared with others, or we may need it to show the effect of this studily, and

- Staff may need to fallow-up with you if there is a medical reason to do so.

To cancel this form, please write to:

Principal Investigator

For IRB Stady \# Pro0019501

2402 W Areele St. Unit 416. Tampar, Fl 33609

While we are canducting the research study, we cannot let you see or copy the information we have about you. After the research is completed, frou can see the infonmation about you.

\section{Privacy and Confidentiality}

We will keep your suty records private and without your name on any foms. Certain people may meed to see your study records. By law, anyone who looks at your records must leep them private. The waly people who will be allowed to see these reconds are:

- The resesrch tesm, including the Principal Inveztigator, advisor, and resauch assistants

- Certain government and university people who meed to know mare about the study. Fiar example, people who provide guidance on this stady may need to look at your records. This is done to make gure that we are doing the study in the right way. They also need to make sure that we are protecting your rights and your safety.

- Any agency of the federal, state, or local government that regulates this research. This inchudes the Departiment of Health and Human. Services (DHHS) and the Office for Human Research Protection (OFRP).

- The USF Institutional Review Board (IRB) and its related staff, who have supervision responsibulities for this study. staff in the USF Office of Research and Innowation, USF Division of Research Integrity and Compliance, and other USF offices that review this research.

We may publish what we learn from this study. If we do, we will not include your name. We will not publish anything that world let psople know who you are. 


\section{Voluntary Participation/ Withdrawal}

You should only take part in this study if you want to volunteer. You should not feel that there is any pressure to take part in the study. You are free to participate in this research or withdraw at any time. There will be no penalty or loss of benefits you are entitled to receive if you stop taking part in this: study.

You can get the answers to your questions, concerns, or complaints

If you have any questions, concerms or complaints about this shudy, or experience an adverse event or unanticipated problem, call Haley Krentz at $(630) 272.3281$.

If you have questions ab-out your rights as a participant in this stady, general questions, or bave complaints, concerns or issues you want to discuss, with someone outside the research, call the USF IRB at (81.3) 974-5638. 


\section{Consent to Take Part in this Research Study}

and Authorization to Collect, Use and Share Your Health Information

It is up to you to decide whether you want to talse part in this study. If you want to take part, please sign the form, if the following statements are true.

I freely give my consent to take part in this study and authorize that my health information as agreed above, be collected/disclased in this study. I understand that by sizning this form I am agreeing to take part in research. I have received a copy of this form to talke with me.

Signature of Person Taking Part in Study

Date

Printed Name of Person Taking Part in Study

\section{Statement of Person Obtaining Informed Consent}

I have carefully explained to the person taking part in the study what be or she can expect from their participation. I hereby certify that when this person signs this form. to the best of ny knowledge, hel she understanis:

- What the study is about:

- What procedures/interventions/investigational drugs or devices will be used-

- What the potentisl benefits might be; and

- What the known risks might be.

I can confirm that this research subject gpealss the hinguage that was used to explain this research and is receining an informed consent form in the appropriate linguage. Additionally, this subject reads well enough to understand this document or. if not, this person is able to hear and understand when the form is read to him or her. This subject does not have a medical'psychological problem that would compromise comprehension and therefore makes it hard to understand what is being explained and can, therefore, give legally effective informed consent. This subject is not under any type of anesthesia or an algesic that may cloud their judgment or make ir hard to understand what is being explained and, therefore, can be considered competent to give informed consent.

Sigmature of Person Obtaining Informed Cansent / Research Authocization

Date

Printed Mame of Person Obtaining If formed Consent/ Reseanch Authorization 


\section{Appendix B:}

Data Sheet

ELTON

Leftover Laps:

Laps Today:

Total Laps:

Breaks:

Reinforcer:

PAUL

Leftover Laps:

Laps today:

Total Laps:

Breaks:

Reinforcer:

JOHN

Leftover Laps:

Laps today:

Total Laps:

Breaks:

Reinforcer:
FRANK

Leftover Laps:

Laps Today:

Total Laps:

Breaks:

Reinforcer:

\section{JERRY}

Leftover Laps:

Laps Today:

Total Laps:

Breaks:

Reinforcer: 


\section{Appendix C:}

\section{Interview Questions}

Potential Interview Questions to Staff/Participants

1. What are some of the participants/your favorite things to do here?

2. Does the participant/you like to play with certain types items/tangibles?

a. i.e. squishy balls, shiny/reflective letters, bubbles, books, etc.

3. What food and drinks does the participant/you prefer?

4. If the participant/you have free time, what does he or she/you like to do?

5. Are there any specific activities this center does already for the participants' contingent on good behavior or task completion?

a. i.e. individual privileges (extra free time, picking activities, etc)

6. what are fun activities that the participant/you would like to do more of?

7. Is there any staff member the participant/you enjoy spending time with? 
Appendix D:

\section{Sample Token Exchange Rate}

Baseline:

- $\quad$ Most active day $=43$ laps

- $\quad$ Least active day $=0$ laps

- $\quad$ Average laps per day $=25$ laps

Hierarchy of Reinforcers from Preference Assessment:

- $\quad$ Most preferred to least preferred (but still a reinforcer)

- $\quad$ CD, coffee cup, diet soda, Gatorade chews, Gatorade

- CD: 125 laps

- $\quad$ Coffee Cup: 100 laps

- Diet Soda: 75 laps

- Gatorade Chews : 50 laps

- Gatorade: 25 laps 


\section{Appendix E:}

\section{Social Validity: Participants}

1. I walk more now than I did before the walking program?

$\begin{array}{ccccc}\text { Strongly Disagree } & \text { Disagree } & \text { Neutral } & \text { Weakly Agree } & \text { Strongly Agree } \\ 1 & 2 & 3 & 4 & 5\end{array}$

2. The walking program was enjoyable.

$\begin{array}{ccccc}\text { Strongly Disagree } & \text { Disagree } & \text { Neutral } & \text { Agree } & \text { Strongly Agree } \\ 1 & 2 & 3 & 4 & 5\end{array}$

3. I feel more physically active now than I did before the walking program started.

$\begin{array}{ccccc}\text { Strongly Disagree } & \text { Disagree } & \text { Neutral } & \text { Agree } & \text { Strongly Agree } \\ 1 & 2 & 3 & 4 & 5\end{array}$

4. I will continue walking after the program is done.

$\begin{array}{ccccc}\text { Strongly Disagree } & \text { Disagree } & \text { Neutral } & \text { Agree } & \text { Strongly Agree } \\ 1 & 2 & 3 & 4 & 5\end{array}$

5. What did you like the most of the program? 


\section{Appendix F:}

\section{Social Validity: Staff}

1. The walking program was feasible with our facility and clients.

$\begin{array}{ccccc}\text { Strongly Disagree } & \text { Disagree } & \text { Neutral } & \text { Agree } & \text { Strongly Agree } \\ 1 & 2 & 3 & 4 & 5\end{array}$

2. The walking program was easily implemented.

$\begin{array}{ccccc}\text { Strongly Disagree } & \text { Disagree } & \text { Neutral } & \text { Agree } & \text { Strongly Agree } \\ 1 & 2 & 3 & 4 & 5\end{array}$

3. I found this program valuable for the participants.

$\begin{array}{ccccc}\text { Strongly Disagree } & \text { Disagree } & \text { Neutral } & \text { Agree } & \text { Strongly Agree } \\ 1 & 2 & 3 & 4 & 5\end{array}$

4. I would consider continuing this program.

$\begin{array}{ccccc}\text { Strongly Disagree } & \text { Disagree } & \text { Neutral } & \text { Agree } & \text { Strongly Agree } \\ 1 & 2 & 3 & 4 & 5\end{array}$

5. Is there anything that you would like to change about the program or how it was run? 
Appendix G:

IRB Approval Letter 


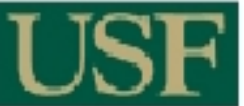

UNIVERSTTY OE

SOUTH FLORIDA
RESEARCH INTEGRTY AND COMPLIANCE

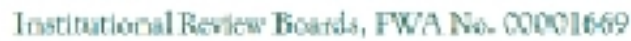

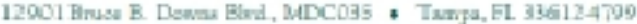

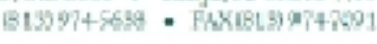

November 3, 2014

Haley Krentz

ABA-Applied Behavior Analysis

Tampa, FL 33612

\section{RE- Expedited Approtial for Tnitial Reriew}

IRB\# P PaO0019501

Title: Using Token Reinforcement to Increase Distnnced Walked for Adults with Intellectusl Disabilities

Study Approwal Feriod: 11/2/2014 to 11/2/2015

Dear Ms. Krentz:

On 11/2/2014, the Institutional Review Board (IRB) reviemed and APFROVED the above application and all documents outlined below.

Approved Item(s):

Protacal Document(s):

$\underline{\underline{R B}}$

Cossent/Asseat Dortument(3) $)^{\text {t: }}$

ConsentFionn v1 10.20.14.pdf

"Please use only the official IR:B stamped informed consent/assent document(i) found under the "Attachments" tab. Please note, these consent/assent document((פ) are anly valid during the approval period indicated at the top of the form('s). 
It was the determination of the $\mathbb{R B}$ that your study qualified for espedited review which inclades activities that (1) present no more than minimal risk to human subjects, and (2) involve only procedures listed in one or more of the categanes autlined below. The IRB may review research through the expedited review procedure authorized by 45 CFR 46.110 and 21 CFR 56.110. The research proposed in this study is categorized under the following expedited review category:

(5) Research involving materialss (data, documents, records, or specimens) that have been collected, or will be collected solely for nonresearch purposes, (such as medical treatment or dingeasis).

(7) Research on individual or group characteristics or behavior (including. bur nor limited to. research on perception, cognition, motivation, identity, languge, communication, caltural beliefs or practices, and social behswior) or refesch employing survey, intervies, oral history. focus group, program evaluation, buman factors evaluation, or quality assurance methodologies.

As the principal investigator of this study. it is your responsibility to conduct this study in accordance with $\mathbb{R} B$ policies and procedures and as approved by the $\mathbb{R} B$. Any changes to the approved research must be submirted to the IRB for review and approval by an amendment.

We appreciate your dedication to the ethical canduct of human subject res earch at the University of South Florida and your continued commitment to thuman reseanch pratections. If you have any questions regarding this manter, please call :813-974-5638.

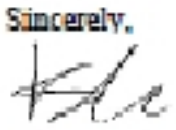<smiles>CC#CC</smiles>

Eristen Salomon, PhD. Vice Clbaimerson USF Instuturions] Review Bosad 